\title{
CORRECTION
}

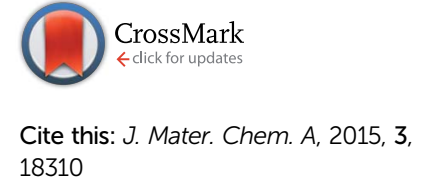

DOI: $10.1039 / \mathrm{c} 5 \operatorname{ta} 90179 \mathrm{k}$

www.rsc.org/MaterialsA
View Article Online

View Journal | View Issue

\section{Correction: A facile method for preparation of self- healing epoxy composites: using electrospun nanofibers as microchannels}

\author{
Vahdat Vahedi, ${ }^{a}$ Pooria Pasbakhsh, ${ }^{* a}$ Siang-Piao Chai ${ }^{\mathrm{b}}$ and Eng-Seng Chan ${ }^{\mathrm{b}}$ \\ Correction for 'A facile method for preparation of self-healing epoxy composites: using electrospun \\ nanofibers as microchannels' by Vahdat Vahedi et al., J. Mater. Chem. A, 2015, 3, 16005-16012.
}

The authors regret the misspelling of two of the author names, Siang-Piao Chai and Eng-Seng Chan, in the original manuscript. The corrected list of authors for this paper is as shown above.

The Royal Society of Chemistry apologises for these errors and any consequent inconvenience to authors and readers. 